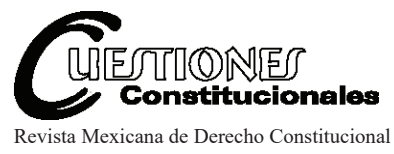

Núm. 38, enero-junio 2018

\title{
EL CONSTITUCIONALISMO INTERNACIONAL Y LA ORGANIZACIÓN MUNDIAL DE COMERCIO: EL CASO DE LOS PROTOCOLOS DE ADHESIÓN
}

\author{
INTERNATIONAL CONSTITUTIONALISM \\ AND THE WORLD TRADE ORGANIZATION: \\ THE CASE OF ACCESSION PROTOCOLS
}

\section{Juliana Peixoto BAtista*}

RESUMEN: El objetivo de este trabajo es examinar los protocolos de adhesión de la OMC y observar en qué medida contribuyen a una mayor armonización y coherencia normativa, en el marco de un proceso de constitucionalización del sistema multilateral de comercio. Según la literatura sobre el tema, el proceso de constitucionalización en el sistema multilateral de comercio se da en dos sentidos: por un lado, existe una transferencia de funciones regulatorias - con inspiración constitucional— desde la esfera nacional hacia la esfera multilateral; por otro, ese proceso de constitucionalización vuelve al ámbito nacional, en forma de obligaciones que los Estados deben cumplir. En tal sentido, primero se hace una revisión de la literatura sobre el constitucionalismo internacional, su surgimiento, evolución y desafíos. Luego, se analiza el proceso de adhesión en el sistema multilateral. Por último, se examinan los protocolos de adhesión, para luego tejer algunas conclusiones.

Palabras clave: constitucionalismo internacional, Organización Mundial de Comercio, protocolos de adhesión.
ABSTRACT: The objective of this article is to analyze the Accession Protocols of the WTO and observe in what extent they contribute to higher levels of rule coherence, in the path for the constitutionalization of the multilateral trading system. According to the literature, the constitutionalization process flows in both directions: on one hand, there is a migration of regulatory functions endowed with constitutional inspiration - from the domestic to the multilateral field; on the other hand, this constitutionalization process returns to the domestic field, in the form of obligations that must be met by WTO members. To that end, first a revision of literature about international constitutionalism as an emerging debate is carried out. Second, the accession process is analyzed. Third, Accession Protocols available in the WTO database are analyzed to bring final remarks.

Keywords: International Constitutionalism, World Trade Organization, Accession Protocols.

* Abogada; investigadora en el Área de Relaciones Internacionales, FLACSO-Arg. 
Esta revista forma parte del acervo de la Biblioteca Jurídica Virtual del Instituto de Investigaciones Jurídicas de la UNAM

Sumario: I. Introducción. II. El constitucionalismo internacional. III. Proceso de adhesión al sistema multilateral de comercio. IV. Análisis de los protocolos de adhesión. V. Conclusiones.

\section{INTRODUCCIÓN}

En años recientes, mucho se ha discutido sobre el constitucionalismo internacional, sobre todo en los albores del siglo XXI, ante el significativo avance de procesos de integración de organizaciones internacionales que se han multiplicado. Este panorama ha creado consensos mínimos que permiten la convivencia de los Estados en la comunidad internacional y contribuye a una creciente uniformización de la vida social. ${ }^{1}$

En ese debate, se enmarcan los estudios constitucionalistas que tratan de indagar sobre un proceso de creciente armonización de las reglas en el sistema internacional. ${ }^{2}$ En tal sentido, desarrollan doctrina sobre los rasgos de ese proceso de constitucionalización internacional, sus atributos, sus impactos. Es una literatura relativamente reciente y si bien no es homogénea, hay una clara predominancia de juristas europeos.

1 Álvarez, José E., "International Organizations: Then and Now", The American Journal of International Law, vol. 100, núm. 2, abril de 2006, pp. 324-347.

2 Schloeman, Hennes y Ohlholff, Stefan, "«Constitutionalization» and Dispute Settlement in the WTO. National Security as an Issue of Competence", American Journal of International Law, vol. 93, núm. 2, abril de 1999, pp. 424-451; Tomuschat, Christian, "International Law as the Constitution of Mankind", en United Nations (ed.), International Law on the Eve of the Twenty-first Century. Views form the International Law Comission, Nueva York, Naciones Unidas, 1999; id., en Derrida, Jacques (colab.), La constelación posnacional, Buenos Aires, Paidós, 2000; id., El derecho internacional en la transición hacia un escenario posnacional. Europa: en defensa de una politica exterior común, Madrid, Katz Editores y CCCB, 2008; Cottier,Thomas y Hertig, Marta, "The Prospects of 21 st Century Constitutionalism", Max Planck Yearbook of United Nations Law, vol. 7, 2003, pp. 261-328; Wet, Erika de, "The International Constitutional Order", International and Comparative Law Quarterly, vol. 55, enero de 2006, pp. 51-76; Loughlin, Martin y Walker, Neil (eds.), The Paradox of Constitutionalism: Constituent Power and Constitutional Form, Oxford University Press, 2008, p. 392; Dunoff, Jeffrey L. y Trachtman, Joel P. (eds.), Ruling the World? Constitutionalism, International Law, and Global Governance, Cambridge, Cambridge University Press, 2009; Dobner, Peter y Loughlin, Martin (eds.), The Twilight of Constitutionalism?, Oxford, Oxford University Press, 2010, entre otros. 
En dicha discusión, los sistemas o regímenes de gobernanza, así como las instituciones internacionales son el objeto de estudio. La Organización de las Naciones Unidas (ONU), la Organización Mundial de Comercio (OMC) o la Unión Europea están entre las paradigmáticas. Al analizarlos, la literatura indaga sobre la importancia de dichos sistemas/instituciones para promover una mayor armonización normativa, coherencia y jerarquización entre normas. En definitiva, un proceso que disminuya los riesgos de la multiplicación y fragmentación normativa y sus consecuencias sobre la seguridad jurídica. En este sentido, se le titula de "proceso de constitucionalización" teniendo en cuenta que se trata una armonización y jerarquización con inspiración constitucional, vale decir, que promueva valores constitucionales como los derechos y las garantías fundamentales, la separación de poderes, la rendición de cuentas, los procesos democráticos.

Con relación a la Organización Mundial de Comercio (OMC), las preguntas de investigación generalmente giran alrededor de si la OMC puede ser o no considerado un caso de constitucionalización en el sistema internacional, y cuáles son las implicancias de ello. ${ }^{3}$ Es un debate muy controvertido, sobre todo teniendo en cuenta que trae a la luz la compleja relación entre los derechos humanos y las libertades de comercio. ${ }^{4}$ De todos modos, en general se toma la creación de la OMC como un hito en esta discusión.

3 Cass, Deborah Z., The Constitutionalization of the World Trade Organization. Legitimacy, Democracy, and Community in the International Trading System, Oxford, Oxford University Press, 2005; Pauwelyn, Joost, "Review of The Constitutionalization of the World Trade Organization: Legitimacy, Democracy, and Community in the International Trading System by Deborah Z. Cass", American Journal of International Law, vol. 100, núm. 4, 2006, pp. 986-991; Peixoto Batista, Juliana, "Armonización y fragmentación de las reglas en el sistema internacional: un acercamiento al caso de la OMC", Revista Relaciones Internacionales, año 25, núm. 50, enero-julio de 2016, pp. 45-74; Dunoff, Jeffrey L. y Trachtman, Joel P. (eds.), Ruling the..., cit.

4 Alston, Philip, "Resisting the Merge and Acquisition of the Human Rights by Trade Law: A Reply to Petersmann”, European Journal of International Law (3), 2002, pp. 815 844; Peers, Steve, "Fundamental Rights or Political Whim? WTO Law and the European Court of Justice", en Búrca, Gráinne de y Scott, Joanne (eds.), The EU and the WTO: Legal and Constitutional Issues, Oxford, Hart Publishing, 2001; Petersmann, Ernst-Ülrich, "Time for Integrating Human Rights into the Law of Worldwide Organizations: Lessons from European Integration Law for Global Integration Law", Jean Monnet Working Paper 7/01, Nueva York, School of Law, 2001, disponible en: http://www.jeanmonnetprogram. org/archive/papers/01/012301.html; id., "Taking Human Dignity, Poverty and Empowerment of Individuals More Seriously: Rejoinder to Alston", Jean Monnet Working Paper, Nueva York, School of Law, núm.12/02, 2002; id., "Constitutionalism and WTO law: from a State-Centered Approach Towards a Human Rights Approach in International 
La pérdida de impulso de las negociaciones comerciales multilaterales hizo que ese debate perdiera empuje, en un escenario de estancamiento de la Ronda de Doha, agudizado desde la crisis global de 2008. Sin embargo, es necesario indagar sobre si dicho estancamiento significa que hay una parálisis del proceso de armonización normativa. Como se verá en este estudio, la respuesta es no.

El objetivo de este trabajo es analizar el proceso de adhesión a la OMC en el marco del debate sobre la constitucionalización del sistema multilateral de comercio. El argumento principal es que los Protocolos de Adhesión promueven una creciente armonización normativa que contribuye al proceso de constitucionalización del sistema multilateral de comercio, iniciado con la creación de la OMC.

El argumento se construye sobre antecedentes en la literatura a los que se suman observaciones empíricas. En este sentido, en primer lugar, con base en la revisión de la literatura y a trabajos previos que hemos realizado, ${ }^{5}$ la creación de la $\mathrm{OMC}$ ha representado un hito en el debate sobre la constitucionalización del sistema internacional. La literatura señala a la OMC como uno de los ejemplos de la llamada migración de funciones con inspiración constitucional desde la esfera nacional hacia esferas internacionales (regionales, globales y multilaterales), aunque esa posición no goza de consenso entre los autores. Luego, el proceso de constitucionalización vuelve al ámbito nacional, en forma de obligaciones estandarizadas que los Estados deben cumplir, en un doble movimiento, como lo afirma Biaggini. ${ }^{6}$ En segundo lugar, se observa en la información empírica recolectada que los Protocolos de Adhesión llevan no sólo a una armonización sino a una homogenización de las reglas por medio del establecimiento de pautas comunes de política comercial y estándares que los Estados deben cumplir para ingresar a la OMC, colaborando con la retroalimentación de ese proceso de constitucionalización.

Economic Law", en Kennedy, David y Southwick, J. (eds.), The Political Economy of International Trade Law, Cambridge, Cambridge University Press, 2002, pp. 32-67; Howse, Robert, "Human Rights in the WTO: Whose Rights, What Humanity? Comment on Petersmann", Jean Monnet Working Paper 12/02, Nueva York, School of Law, 2002. Disponible en: http://ejil.org/pdfs/13/3/489.pdf; Dunoff, Jeffrey L. y Trachtman, Joel P. (eds.), Ruling..., cit.

5 Peixoto Batista, Juliana, “Armonización y fragmentación...," cit.

6 Citado en Cottier, Thomas y Hertig, Marta, "The Prospects of...", cit., pp. 269. 
Este trabajo se divide tres partes. En primer lugar, se hace una revisión de la literatura sobre el constitucionalismo internacional, marco teórico de este trabajo, para traer a la luz sus principales argumentos y cómo la OMC es analizada bajo esa corriente teórica. En segundo lugar, se analiza el proceso de adhesión en el sistema multilateral, desde el Acuerdo General de Aranceles Aduaneros y Comercio (GATT, por sus siglas en inglés) y en tercer lugar, se analizan los protocolos de adhesión disponibles en la base de datos de la OMC. Por último, se tejen algunas conclusiones.

\section{EL CONSTITUCIONALISMO INTERNACIONAL}

La literatura dedicada a la constitucionalización se inspira en el término "Constitución" entendido como Constitución moderna occidental, herencia de las paradigmáticas revoluciones liberales (francesa y estadounidense) de los siglos XVIII y XIX. Además, la discusión se proyecta al plano internacional con marcada inspiración neokantiana, ${ }^{7}$ aunque existen autores con posiciones más moderadas acerca del fenómeno de constitucionalización del derecho internacional. ${ }^{8}$ Uno de los debates centrales en la literatura acerca del constitucionalismo internacional es la relación entre el Estado y los ámbitos regionales (procesos de integración, por ejemplo) y globales. Autores como Tomuschat, ${ }^{9}$ reconocido como uno de los principales juristas modernos del constitucionalismo internacional, defienden la formación de una comunidad legal global con un núcleo de valores compartidos. El autor invierte la noción usualmente aceptada de legitimidad democrática de la comunidad internacional para expresar que no existe una delegación de poderes por parte del Estado hacia la comunidad internacional sino que el Estado sería un agente de la comunidad global, utilizado para la implementación del núcleo de valores compartidos. El derecho internacional sería entonces un paso intermedio en el proceso de formación de dicha comunidad. En este sentido, el autor afirma que el Estado viene

7 Tomuschat, Christian, "International..., cit.; Habermas, Jürgen "Remarks on Dieter Grimm's «Does Europe Need of Constitution?»”, ELJ, núm. 1, 1995; Wet, Erika de, "The International...", cit.

8 Cottier, Thomas y Hertig, Marta, "The Prospects of...", cit.; Loughlin, Martin y Walker, Neil (eds.), The Paradox of..., cit.; Dunoff, Jeffrey L. y Trachtman, Joel P. (eds.), Ruling the..., cit.; Dobner, Peter y Loughlin, Martin (eds.), The Twilight..., cit.

9 Idem. 
perdiendo su característica de guardián de los intereses comunes de sus ciudadanos y que las instituciones regionales y globales deben compensar esas pérdidas. ${ }^{10}$

Así, el constitucionalismo en el ámbito internacional, sea en esferas regionales o globales, puede ser descrito como un proceso de desestatización, resultado de la reducción de la capacidad regulatoria del Estado, y consiste en la transferencia de políticas tradicionalmente reguladas por el derecho doméstico hacia regímenes o estructuras de gobernanza internacional o supranacional, en una de migración de funciones constitucionales hacia el derecho internacional. ${ }^{11}$ Ello afecta directamente el campo de estudio del derecho internacional y, según Giovanni Biagginni, "el derecho constitucional se torna cada vez más internacional, mientras que el derecho internacional se torna cada vez más constitucional". ${ }^{12}$ En este sentido, la función tradicional del derecho internacional estaría ahora suplementada por una función constitucional. ${ }^{13}$

Más aún, para Cottier ${ }^{14}$ la causa de dicho cambio en la función del derecho internacional reside de manera muy marcada en los derechos humanos y en el comercio internacional, dado el reciente y vertiginoso proceso de globalización. Ambos, a lo largo del siglo XX, desdibujaron las fronteras entre lo doméstico y lo internacional y establecieron estándares internacionales a ser alcanzados por todos los Estados. En efecto, según el autor, ambas ramas del derecho internacional son expresiones del liberalismo, ingredientes esenciales del orden de la postsegunda guerra mundial. Imponen fronteras y al mismo tiempo requerimientos positivos al Estado y se erigieron como respuestas al fenómeno de los totalitarismos que habían absorbido por completo al individuo. Acorde a ese planteo, Habermas ${ }^{15}$ afirma que los derechos humanos constituirían el código moral de la normativa

10 Citado en Bogdandy, Armin Von, "Constitutionalism in International Law: Comment on a Proposal from Germany”, Harvard International Law Journal, vol. 47, 2006, pp. 223-242.

11 Cottier, Thomas y Hertig, Marta, “The Prospects of...”, cit.; Dunoff, Jeffrey L. y Trachtman, Joel P. (eds.), Ruling the..., cit.; Tsagourias, Nicholas (ed.), Transnational Constitutionalism-International and European Perspectives, Cambridge, Cambridge University Press, 2007.

12 Citado en Cottier, Thomas y Hertig, Marta, ibidem, p. 269.

13 Tomuschat, Christian, "International...", cit.

14 Cottier, Thomas y Hertig, Marta, "The Prospects of...", cit.

15 Idem. 
internacional básica que debe estructurar las reglas de convivencia entre los Estados. Así, el código legal en que se basa esa constelación posnacional es la Declaración Universal de los Derechos Humanos, cuya aplicación en los ámbitos nacional, regional, internacional, así como no gubernamental, es la principal y más legítima fuerza que está detrás de la creciente constitucionalización en el plano internacional.

A partir de la teorización de los orígenes del constitucionalismo en el plano internacional, los autores se abocan a definir y caracterizar dicho fenómeno, llamado mayormente de "constitucionalización". En este sentido, surgen varias construcciones teóricas. Algunos afirman que el proceso de constitucionalización en la esfera internacional tiene reglas procedimentales y sustantivas básicas ${ }^{16} \mathrm{y}$ que dicho fenómeno está compuesto por niveles de gobernanza, hecho que lo caracteriza como un constitucionalismo multinivel. ${ }^{17}$ Dicho proceso de múltiples niveles, policéntrico, va más allá del tradicional procedimiento constitucional y de las discusiones sobre jerarquía de normas para incluir una red de soberanías y poderes difusos, ${ }^{18}$ como las diversas esferas de gobernanza (internacionales, regionales, nacionales, locales).

Algunos autores ahondan en la discusión en búsqueda de características básicas que permitan identificar el fenómeno de constitucionalización en el sistema internacional. Walker, Tsagourias, Frank, Dunoff y Tachtman ${ }^{19}$ sostienen entonces que deberían cumplirse algunas dimensiones o aspectos para que se pueda afirmar que un sistema de normas está atravesando un proceso de constitucionalización. Entre las dimensiones que detallan los autores, se encuentran la existencia de una norma fundacional; la creación de órganos de gobernanza; la delineación de esferas de competencia; la existencia de un órgano interpretativo de las normas o sea, función judicial; la existencia de condiciones de membresía, entre otros. En dicha discusión, los sistemas o regímenes de gobernanza, así como las instituciones internacionales componen el objeto de estudio. Como se ha mencionado, la

\footnotetext{
16 Wet, Erika de, "The International...", cit.

17 Cottier, Thomas y Hertig, Marta, “The Prospects of...”, cit.

18 Carrozza, Paolo, Carrozza, P., “Constitutionalism's Post-Modern Opening”, en
} Loughlin, Martin y Walker, Neil, (eds.), The Paradox of..., cit.

19 Walker, Neil, "The EU and the WTO: Constitutionalism in a New Key", en Búrca, Gráinne de y Scott, Joanne (eds.), The EU and the..., cit.; Tsagourias, Nicholas (ed.), Transnational Constitutionalism, cit.; Frank, Thomas, "Preface: International Institutions: Why Constitutionalize", en Dunoff, Jeffrey y Trachtman, Joel P. (eds.), Ruling the..., cit. 
Organización de las Naciones Unidas (ONU), la Organización Mundial de Comercio (OMC) o la Unión Europea están entre las analizadas.

Este debate de amplio espectro se traslada de dos formas al sistema multilateral de comercio, dada la ampliación de sus funciones a partir de la creación de la OMC en 1995. Por un lado, están los autores que defienden la necesidad de integrar los derechos humanos y su lógica constitucional a la OMC $y$, en medio de ello, el debate acerca de si la libertad de comercio es o no "constitucional", o si dicha libertad es o no un derecho fundamental. ${ }^{20}$ Ese debate tiene su raíz en el hecho de que muchos de los autores consideran que la constitucionalización supone, además de ciertos procedimientos, un núcleo de valores relacionado entre otras cosas con garantías fundamentales. Por otro lado, se encuentra la discusión sobre si la creación de la OMC significó o no un avance en el proceso de a constitucionalización del régimen multilateral de comercio. ${ }^{21}$

El enfoque no está exento a críticas. De hecho, el solo uso del término constitucionalización en el ámbito del sistema internacional y en el sistema multilateral de comercio suscita muchas controversias. En tal sentido, Petersmann sostiene, por un lado, que los acuerdos de la OMC deben tener una función constitucional porque el proteccionismo, en tanto política selectiva, inexorablemente afecta los intereses de la mayoría. ${ }^{22}$ Los acuerdos de la OMC deben "atar de manos" a los gobernantes para que resistan la presión de los grupos de interés y para que de esta manera puedan promover un régimen de libre comercio internacional de la mano de un régimen democrático nacional. ${ }^{23}$ Por otro lado, autores como Pauwelyn, ${ }^{24}$ afirman que la existencia de un fenómeno de creciente constitucionalización en el sistema multilateral de comercio con la creación de la OMC es innegable; mientras

20 Alston, Philip, "Resisting the Merge...", cit.; Peers, Steven, "Fundamental Rights...”, cit.; Petersmann, Ernst-Ülrich, "Time for Integrating Human Rights...”, cit.; Howse, Robert, "Human Rights in...", cit.; Dunoff, Jeffrey y Trachtman, Joel P. (eds.), Ruling the..., cit.

21 Schloeman, Hennes y Ohlholff, Stefan, “«Constitutionalization» and...”, cit.; Cass, Deborah Z., The Constitutionalization ..., cit.; Pauwelyn, Joost, "Review of...", cit.

22 Petersmann, Ernst-Ülrich, "Constitutionalism and WTO Law...", cit.

23 McGinnis, John O. y Movsesian, Mark L., "The World Trade Constitution", Harvard Law Review, vol. 114, 2000, pp. 511-605, disponible en http://ssrn.com/abstract $=274520$ or http://dx.doi.org/10.2139/ssrn.274520

24 Idem. 
otros como Tachtman, Débora Cass, Howse y Nicholaidis ${ }^{25}$ recomiendan evitar el uso del término "constitucionalización", teniendo en cuenta otros aspectos de la $\mathrm{OMC}$, como su falta de legitimidad democrática, característica esencial para cualquier orden que se dé en llamar constitucional.

Como se puede observar, el problema de la legitimidad en el plano internacional es recurrente entre los críticos del constitucionalismo internacional. Desde adentro mismo del enfoque constitucionalista, algunos autores reconocen las tensiones que existen relacionadas con la falta de legitimidad democrática del sistema internacional en general y del derecho internacional en particular. Autores como Cottier y Hertig ${ }^{26}$ reconocen que la tensión existente entre los requerimientos de legitimidad y eficiencia en el plano internacional impacta directamente sobre la discusión, aumentando su complejidad. Asimismo, Tomuschat ${ }^{27}$ afirma que la comunidad global está basada en valores compartidos que funcionan como el sustrato social del derecho internacional, pero no como fuente de legitimidad democrática. Para el autor, el derecho internacional poseería credenciales democráticas solamente de manera derivada y por eso el modelo de constitucionalismo internacional no se puede construir como mera reproducción del modelo de constitucionalismo nacional o doméstico, que sí posee legitimidad democrática, aunque sea discutida. De Wet, Dunoff y Trachtman ${ }^{28}$ apuntan en la misma dirección para afirmar que la raíz del error es, por un lado, utilizar la gobernanza democrática nacional como modelo para la gobernanza internacional y, por el otro, equiparar democracia con legitimidad. Ambos llevan a que el déficit democrático a nivel internacional no pueda superarse nunca. Para dichos autores, la solución sería mejorar la calidad de la representación y de la participación en el nivel internacional, contribuyendo a la legitimidad en el plano internacional.

Claramente la discusión se relaciona más con los beneficios o perjuicios de una mayor constitucionalización del sistema multilateral de comercio

25 Dunoff, Jeffrey L. y Tachtman, Joel (eds.), op. cit.; Cass, Deborah Z., The Constitutionalization..., cit.; Howse, Robert y Nicolaidis, Kalypso, "Legitimacy and Global Governance: Why Constitutionalizing the WTO is a Step Too Far", en Porter, R. et al. (eds.), Efficiency, Equity, and Legitimacy: the Multilateral Trading System at the Millennium, Brooking Institution, 2001.

26 Idem.

27 Idem.

28 Wet, Erika de, “The International...”, cit.; Dunoff, Jeffrey y Trachtman, Joel P. (eds.), Ruling the..., cit. 
que con el proceso en sí. En este sentido, se denota que en general el proceso de armonización del sistema multilateral de comercio con la creación de la OMC es aceptado por la mayor parte de los autores, lo que difiere es el uso de términos derivados del constitucionalismo para referirse a ello.

En otro trabajo, hemos señalado que la creación de la $\mathrm{OMC}$ ha sido un paso relevante en el proceso de constitucionalización del sistema multilateral de comercio, tomando en cuenta las dimensiones de constitucionalización que gozan de mayor consenso en la literatura si se lo compara con relación a su antecesor el GATT, ${ }^{29}$ teniendo en cuenta las principales dimensiones identificadas por la literatura como la existencia de una norma fundante, la creación de órganos de gobernanza; la delineación de esferas de competencia; la existencia de un órgano interpretativo de las normas (función judicial); la existencia de condiciones de membresía; entre otros. Así, este trabajo no vuelve sobre esa discusión, ya saldada, y en cambio analiza en qué medida dicho proceso avanza, de la mano de los protocolos de adhesión de la OMC. Es decir, el presente trabajo dará un paso más allá de la discusión sobre la creación de la OMC como hito del proceso de constitucionalización del sistema internacional, para indagar en qué medida el proceso de adhesión colabora con el avance de esa constitucionalización al proponer reglas homogéneas.

En el próximo apartado, empezaremos a analizar el proceso de adhesión del sistema multilateral de comercio, durante la vigencia del GATT/47 y posteriormente durante la vigencia de la OMC para observar la capacidad de armonización de ese proceso.

\section{Proceso De ADHESIÓN AL SISTEMA MULTILATERAL DE COMERCIO}

En septiembre de 2016, la OMC contaba con 164 miembros, 20 observadores (19 países y la Santa Sede) y decenas de organizaciones internacionales también en condición de observadores de los diferentes órganos del sistema multilateral (FMI, Banco Mundial, UNCTAD, OECD, Organización Mundial de la Salud-OMS, Organización Internacional del TrabajoOIT, FAO, ISO, etcétera). ${ }^{30}$ La membresía es prácticamente universal: incluye a todos los países de más peso en el comercio internacional y a la

29 Peixoto Batista, Juliana, “Armonización y fragmentación...", cit.

30 Cfr., www.wto.org (consultada el 22 de septiembre de 2016). 
mayoría de los países en desarrollo de reciente liberalización luego de la caída de la URSS y nuclea cerca del 92\% de la población mundial y 95\% del comercio mundial. ${ }^{31}$ Una parte considerable de dichos miembros (73) lo son desde la creación misma de la $\mathrm{OMC}$, ya sea porque eran miembros originales del GATT/47, o bien porque su adhesión se produjo durante la Ronda Uruguay y coincidió con la creación de la OMC.

Al observar esas cifras, se percibe que la adhesión a la OMC es en sí mismo un tema muy relevante, dado que a través de los protocolos se fijan pautas básicas que regulan la actividad de los Estados en el comercio internacional. Por ello, es importante indagar si esos protocolos contribuyen o no a la armonización normativa en el sistema multilateral de comercio, lo que contribuiría entonces a la constitucionalización de dicho sistema.

En este apartado, se hará un breve recorrido por las reglas para la adhesión al sistema multilateral, desde la Carta de la Habana hasta la OMC y luego se analizarán los protocolos de adhesión disponibles en la base de datos de la OMC. El objetivo es observar en qué medida esos protocolos son armonizados y armonizadores en el camino hacia el proceso de constitucionalización iniciado con la creación de la OMC.

\section{En la Carta de La Habana y en el GATT de 1947}

El capítulo VII de la Carta de La Habana trataba específicamente sobre la Organización Internacional de Comercio (OIC) y en su artículo 71 estipulaba las condiciones de membresía. Según el documento, serían miembros originarios de la $\mathrm{OIC}$ :

a) los Estados invitados a la Conferencia de las Naciones Unidas sobre Comercio y Empleo, cuyos gobiernos acepten la presente Carta, a más tardar el 30 de septiembre de 1949, conforme a las disposiciones del párrafo 1 del artículo 103 o, en caso de que la Carta no haya entrado en vigor en esa fecha, los Estados cuyos gobiernos convengan en poner en vigor esta Carta, conforme a las disposiciones del inciso b) del párrafo 2 del artículo 103;

b) los territorios aduaneros separados invitados a la Conferencia de las Naciones Unidas sobre Comercio y Empleo, en cuyo nombre los miembros

\footnotetext{
31 Den Bossche, Peter van, The Law and Policy of the World Trade Organization. Text, cases and materials, The Royal Institute of International Affairs, Cambridge, Cambridge University Press, 2005, p. 103.
} 
competentes acepten la presente Carta, a más tardar el 30 de septiembre de 1949, conforme a las disposiciones del artículo 104 o, en caso de que la Carta no haya entrado en vigor en esa fecha, aquellos territorios aduaneros separados que convengan en poner en vigor esta Carta, conforme a las disposiciones del inciso b) del párrafo 2 del artículo 103, en cuyo nombre el miembro competente acepte la Carta conforme a las disposiciones del artículo 104. Si, para la fecha en que desee depositar su instrumento de aceptación de la Carta, alguno de dichos territorios aduaneros ha asumido la plena responsabilidad oficial de sus relaciones diplomáticas, procederá en la forma prevista en el inciso a) del presente párrafo.

Asimismo, establecía que cualquier otro Estado cuya admisión hubiere sido aprobada por la Conferencia, llegaría a ser miembro de la OIC desde que hubiese aceptado la Carta y sus enmiendas (artículo 71:2). Con relación a los territorios aduaneros no invitados a la Conferencia de las Naciones Unidas sobre Comercio y Empleo, podrían llegar a ser miembros si se dieran algunas condiciones: el territorio debería ser propuesto como miembro por el miembro competente a quien corresponda la responsabilidad oficial de sus relaciones diplomáticas; el territorio debería gozar de autonomía en la dirección de sus relaciones comerciales exteriores y de las otras materias previstas en esta Carta; su admisión debería ser aprobada por la Conferencia. En ese caso, los territorios podrían ser miembros cuando el miembro competente aceptara la Carta en nombre de tal territorio o bien, si se trata de un territorio respecto al cual la Carta haya sido aceptada ya en virtud de ese artículo, cuando la Conferencia aprobara la admisión de ese territorio después de que el mismo hubiera adquirido su autonomía (artículo 71: 3).

La Carta estipulaba aun condiciones de membresía para territorios en regímenes especiales, por ejemplo, territorio bajo administración fiduciaria de las Naciones Unidas o sometidos a ocupación militar (artículo 71: 4 y 5).

Ante el fracaso de la Carta de La Habana y consecuentemente de la OIC, el GATT entró en vigencia. Teniendo en cuenta su condición de acuerdo y en ausencia de una estructura institucional más desarrollada, el GATT contaba con un solo artículo sobre la adhesión a dicho acuerdo. Así, según su artículo XXXIII

todo gobierno que no sea parte en el presente Acuerdo o todo gobierno que obre en nombre de un territorio aduanero distinto que disfrute de completa autonomía en la dirección de sus relaciones comerciales exteriores y en las 
demás cuestiones tratadas en el presente Acuerdo, podrá adherirse a él en su propio nombre o en el de dicho territorio, en las condiciones que fijen dicho gobierno y las partes contratantes. Las decisiones a que se refiere este párrafo las adoptarán las partes contratantes por mayoría de los dos tercios.

El GATT de 1947 sufrió varias modificaciones a lo largo de su vigencia y en el ámbito de sus rondas de negociaciones. Asimismo, en el momento de la primera Ronda del GATT/47, que se realizó en 1947, había 23 países miembros. Antes de finalizar la Ronda Uruguay, en 1994, 128 países ya habían firmado el GATT en calidad de "partes contratantes", como se puede ver en el siguiente cuadro.

Cuadro 1. Las rondas de negociación del GATT de 1947, sus temas y la cantidad de países participantes

\begin{tabular}{|c|c|c|c|}
\hline Año & Lugar/denominación & Temas abarcados & Países \\
\hline 1947 & Ginebra & Aranceles & 23 \\
\hline 1949 & Annecy & Aranceles & 13 \\
\hline 1951 & Torquay & Aranceles & 38 \\
\hline 1956 & Ginebra & Aranceles & 26 \\
\hline 1960-1961 & $\begin{array}{c}\text { Ginebra } \\
\text { (Ronda Dillon) }\end{array}$ & Aranceles & 26 \\
\hline 1964-1967 & $\begin{array}{c}\text { Ginebra } \\
\text { (Ronda Kennedy) }\end{array}$ & $\begin{array}{l}\text { Aranceles y medidas anti- } \\
\text { dumping. }\end{array}$ & 62 \\
\hline 1973-1979 & $\begin{array}{c}\text { Ginebra } \\
\text { (Ronda de Tokio) }\end{array}$ & $\begin{array}{l}\text { Aranceles, medidas no aran- } \\
\text { celarias y acuerdos relativos } \\
\text { al marco jurídico. }\end{array}$ & 102 \\
\hline 1986-1994 & $\begin{array}{c}\text { Ginebra } \\
\text { (Ronda Uruguay) }\end{array}$ & $\begin{array}{l}\text { Aranceles, medidas no aran- } \\
\text { celarias, normas, servicios, } \\
\text { propiedad intelectual, solu- } \\
\text { ción de diferencias, textiles, } \\
\text { agricultura, creación de la } \\
\text { OMC, etcétera. }\end{array}$ & 123 \\
\hline
\end{tabular}

FUENTE: www.wto.org. 
2. Proceso de adhesión en los Acuerdos de Marrakech (OMC)

El 1o. de enero de 1995, la OMC entró en vigencia y sustituyó al GATT. Algunos de los países que ya eran parte del GATT/47, así como aquellos que ingresaron en el momento de cierre de la ronda y creación de la $\mathrm{OMC}$, pasaron a ser "Miembros (iniciales) de la OMC" y su fecha de adhesión formal pasó a ser el 1o. de enero de 1995, como muestra el siguiente cuadro:

Cuadro 2. Miembros de la OMC al 1o. de enero de 1995 (por orden alfabético)

\begin{tabular}{|l|l|l|l|l|}
\hline Alemania & $\begin{array}{l}\text { Corea, } \\
\text { República de }\end{array}$ & $\begin{array}{l}\text { Hong Kong, } \\
\text { China }\end{array}$ & Mauricio & Rumania \\
\hline $\begin{array}{l}\text { Antigua y } \\
\text { Barbuda }\end{array}$ & Costa Rica & Hungría & México & Santa Lucía \\
\hline Argentina & Côte d'Ivoire & India & Myanmar & $\begin{array}{l}\text { San Vicente y } \\
\text { las Granadinas }\end{array}$ \\
\hline Australia & Dinamarca & Indonesia & Namibia & Senegal \\
\hline Austria & Dominica & Irlanda & Nigeria & Singapur \\
\hline $\begin{array}{l}\text { Bahrein, } \\
\text { Reino de }\end{array}$ & España & Islandia & Noruega & Sri Lanka \\
\hline Bangladesh & $\begin{array}{l}\text { Estados Uni- } \\
\text { dos de América }\end{array}$ & Italia & $\begin{array}{l}\text { Nueva } \\
\text { Zelandia }\end{array}$ & Sudáfrica \\
\hline Barbados & Filipinas & Japón & Países Bajos & Suecia \\
\hline Bélgica & Finlandia & Kenya & Paquistán & Suriname \\
\hline Belice & Francia & $\begin{array}{l}\text { Kuwait, Estado } \\
\text { de }\end{array}$ & Paraguay & Swazilandia \\
\hline Brasil & Gabón & Luxemburgo & Perú & Tailandia \\
\hline $\begin{array}{l}\text { Brunei Darus- } \\
\text { salam }\end{array}$ & Ghana & Macao, China & Portugal & Tanzanía \\
\hline Bulgaria & Grecia & Malasia & Reino Unido & Uganda \\
\hline Canadá & Guyana & Malta & $\begin{array}{l}\text { República } \\
\text { Checa }\end{array}$ & \\
\hline Chile & Honduras & Marruecos & $\begin{array}{l}\text { República } \\
\text { Eslovaca }\end{array}$ & \\
\hline
\end{tabular}

FuENTE: OMC, www.wto.org. 
A partir de la vigencia de las reglas de la Carta de la OMC (artículo XI, XII del Acuerdo y sus notas explicativas anexas), los miembros pueden ser tanto países como territorios aduaneros separados (por ejemplo, Hong Kong). Asimismo, existen dos formas para que los países puedan ser miembros:

- Miembros iniciales: el artículo XI de la Carta estipula que las partes contratantes del GATT de 1947 en la fecha de entrada en vigor del presente Acuerdo, y las Comunidades Europeas, que acepten el presente Acuerdo y los Acuerdos Comerciales Multilaterales y para las cuales se anexen Listas de Concesiones y Compromisos al GATT de 1994, y para las cuales se anexen Listas de Compromisos Específicos al AGCS, pasarán a ser miembros iniciales de la OMC. Este camino estuvo disponible hasta marzo de 1997.

- Adhesiones posteriores: el artículo XII de la Carta de la OMC (heredero del artículo XXXIII del GATT) establece que todo Estado o territorio aduanero distinto que disfrute de plena autonomía en la conducción de sus relaciones comerciales exteriores y en las demás cuestiones tratadas en el Acuerdo de la OMC y en los Acuerdos Comerciales Multilaterales podrá adherirse al Acuerdo en condiciones que habrá de convenir con la OMC. Las decisiones en materia de adhesión serán adoptadas por la Conferencia Ministerial, que aprobará el acuerdo sobre las condiciones de adhesión por mayoría de dos tercios de los miembros de la OMC.

El proceso por el cual un país pasa a ser miembro de la OMC es largo y minucioso, y difiere mucho del estilo laisez faire del GATT. De igual modo, como observación general, según el artículo XII del Acuerdo sobre la OMC, la adhesión a dicho organismo se llevará a cabo en las "condiciones que habrá de convenir" y eso quiere decir que dicha adhesión es en esencia un proceso de negociación, como lo expresa la propia OMC. ${ }^{32}$ Puesto que los grupos de trabajo encargados de las adhesiones adoptan sus decisiones por consenso, todos los miembros de la OMC interesados deben coincidir en que han sido atendidas sus preocupaciones y que han quedado resueltas

32 Véase "Para entender la OMC", disponible en www.wto.org (consultada el 22 de septiembre de 2016). 
todas las cuestiones pendientes en el curso de las negociaciones bilaterales y multilaterales. Hasta concluir este proceso, la documentación examinada por el Grupo de Trabajo encargado de la adhesión durante el proceso de negociación tiene carácter reservado.

Hay varios pasos en el proceso de adhesión, como se puede ver en el cuadro que sigue a continuación.

\section{Cuadro 3. Etapas del proceso de adhesión a la OMC}

\begin{tabular}{|l|l|}
\hline $\begin{array}{l}\text { Solicitud de } \\
\text { adhesión }\end{array}$ & $\begin{array}{l}\text { El proceso de adhesión se inicia con la presentación por es- } \\
\text { crito, por parte del gobierno de que se trate, de una solicitud } \\
\text { oficial de adhesión. El Consejo General examina la solicitud } \\
\text { y establece un Grupo de Trabajo cuyo mandato es examinar la } \\
\text { solicitud de adhesión y, en último término, presentar al Con- } \\
\text { sejo General para su aprobación las conclusiones del Grupo de } \\
\text { Trabajo. Pueden formar parte del Grupo de Trabajo todos los } \\
\text { miembros de la OMC. }\end{array}$ \\
\hline $\begin{array}{l}\text { Presentación un memo- } \\
\text { rándum }\end{array}$ & $\begin{array}{l}\text { El gobierno solicitante presenta al Grupo de Trabajo un memo- } \\
\text { rándum que abarca todos los aspectos de su régimen de comer- } \\
\text { cio y su sistema jurídico. Este memorándum constituye la base } \\
\text { del análisis fáctico detallado que realizará el Grupo de Trabajo. } \\
\text { En las reuniones ulteriores del Grupo de Trabajo se examinarán } \\
\text { las preguntas formuladas por los miembros de la OMC sobre la } \\
\text { base de la información proporcionada en el memorándum y de } \\
\text { las respuestas facilitadas por el gobierno solicitante. }\end{array}$ \\
\hline $\begin{array}{l}\text { Condiciones } \\
\text { de adhesión }\end{array}$ & $\begin{array}{l}\text { Tras examinar todos los aspectos relacionados con el régimen } \\
\text { de comercio y el sistema jurídico del gobierno que solicita la } \\
\text { adhesión, el Grupo de Trabajo acomete la parte sustantiva de } \\
\text { las negociaciones multilaterales que se desarrollan en el mar- } \\
\text { co del proceso de adhesión. En esta etapa se determinan las } \\
\text { condiciones de la adhesión del gobierno solicitante. Dichas } \\
\text { condiciones incluyen el compromiso de observar las normas } \\
\text { y disciplinas de la OMC una vez formalizada la adhesión y } \\
\text { los periodos de transición que se requieran para proceder a las } \\
\text { modificaciones legislativas o estructurales que sean necesarias } \\
\text { para aplicar dichos compromisos. }\end{array}$ \\
\hline
\end{tabular}




\begin{tabular}{|c|c|}
\hline $\begin{array}{l}\text { Negociacio- } \\
\text { nes bilaterales }\end{array}$ & $\begin{array}{l}\text { Al mismo tiempo, el gobierno solicitante entabla negociacio- } \\
\text { nes bilaterales con los miembros interesados del Grupo de } \\
\text { Trabajo en relación con las concesiones y los compromisos en } \\
\text { materia de acceso a los mercados para los bienes y servicios. } \\
\text { Los resultados de estas negociaciones bilaterales se incorporan } \\
\text { a la documentación final de adhesión. }\end{array}$ \\
\hline $\begin{array}{l}\text { Documentos } \\
\text { finales de } \\
\text { adhesión }\end{array}$ & $\begin{array}{l}\text { El conjunto consta de tres documentos que representan los re- } \\
\text { sultados de las negociaciones multilaterales y bilaterales men- } \\
\text { cionadas anteriormente. Se trata de los instrumentos siguientes: } \\
\text { — el informe del Grupo de Trabajo que incluye un resumen } \\
\text { de las actuaciones y de las condiciones de adhesión; } \\
\text { - el Protocolo de Adhesión; y } \\
\text { - las listas de compromisos en materia de acceso a los mer- } \\
\text { cados para los bienes y servicios convenidas entre el go- } \\
\text { bierno que solicita la adhesión y los miembros de la OMC. }\end{array}$ \\
\hline $\begin{array}{l}\text { Aprobación } \\
\text { de los instru- } \\
\text { mentos de } \\
\text { adhesión }\end{array}$ & $\begin{array}{l}\text { Cuando los miembros del Grupo de Trabajo consideran que el } \\
\text { proyecto de informe, el Protocolo de Adhesión y los compro- } \\
\text { misos en materia de acceso a los mercados para los bienes y } \\
\text { servicios han quedado finalizados de manera satisfactoria, los } \\
\text { instrumentos relativos a la adhesión se adoptan en una última } \\
\text { reunión oficial del Grupo de Trabajo. } \\
\text { Los documentos se presentan a continuación al Consejo Ge- } \\
\text { neral o a la Conferencia Ministerial para su adopción. La CM } \\
\text { o el CG toman la decisión de aceptar (o no) al nuevo miembro } \\
\text { por consenso, o en su defecto, por mayoría. Una vez aproba- } \\
\text { dos por el Consejo General o por la Conferencia Ministerial, el } \\
\text { conjunto de documentos de adhesión se vuelve a distribuir sin } \\
\text { carácter reservado. }\end{array}$ \\
\hline $\begin{array}{l}\text { Publicación } \\
\text { de los docu- } \\
\text { mentos de } \\
\text { adhesión }\end{array}$ & $\begin{array}{l}\text { Se publicarán dos documentos finales: } \\
\text { — la Decisión del Consejo General; y } \\
\text { _ el Protocolo de Adhesión del nuevo miembro anexo al infor- } \\
\text { me, en el que se indica que el país se adhiere al Acuerdo sobre } \\
\text { la OMC, se definen las listas de compromisos y se señalan las } \\
\text { disposiciones finales relativas al plazo de aceptación del Pro- } \\
\text { tocolo y a la incorporación como miembro de pleno derecho } \\
\text { de la OMC. }\end{array}$ \\
\hline
\end{tabular}




\begin{tabular}{|l|l|}
\hline $\begin{array}{l}\text { Miembro de } \\
\text { pleno derecho }\end{array}$ & $\begin{array}{l}\text { Una vez aprobado por el Consejo General o la Conferencia } \\
\text { Ministerial, el solicitante puede proceder a la firma del Pro- } \\
\text { tocolo de Adhesión e indicar que acepta el conjunto de docu- } \\
\text { mentos de adhesión aprobado, pendiente de la ratificación en } \\
\text { su parlamento nacional. Normalmente se da un plazo de tres } \\
\text { meses a partir de la fecha de la firma del Protocolo de Adhesión } \\
\text { para concluir el procedimiento de ratificación. } \\
\text { Treinta días después de que el gobierno solicitante haya no- } \\
\text { tificado a la Secretaría de la OMC que ha finalizado sus pro- } \\
\text { cedimientos de ratificación, el gobierno solicitante pasa a ser } \\
\text { miembro de pleno derecho de la OMC. }\end{array}$ \\
\hline
\end{tabular}

FUENTE: OMC, www.wto.org.

A septiembre de 2016, diecinueve países habían negociado su adhesión a la OMC. ${ }^{33}$ Según se verá en el próximo apartado y como se desprende de los artículos XVI:4 y XVI:5, los miembros de la OMC deben garantizar que sus legislaciones, regulaciones y disposiciones administrativas estén en conformidad con el Acuerdo, sin reservas. Existen solamente dos excepciones a esta regla:

— “Exención de obligaciones" del artículo IX:3 y IX:4 del Acuerdo de la OMC. Puede invocarse en situaciones excepcionales, en las que es problemático para el país ceñirse a las obligaciones de la OMC. La CM (o el CG) es quien autoriza la exención. En casos en que se prolongue por más de un año, hay una revisión anual para ver si corresponde que continúe; hasta ahora, todas las revisiones han sido formales, es decir, se mantienen las exenciones.

— “Cláusula de no aplicación”. Prevista en el artículo XIII del Acuerdo de la OMC, permite a un miembro evitar que algunas reglas de la $\mathrm{OMC}$ se apliquen en su relación con otro miembro. La cláusula debe invocarse y notificarse a la CM (o el CG) en el momento que el nuevo miembro se une a la OMC. La importancia práctica de esta cláusula ha sido acotada, salvo en el caso de Estados Unidos en su relación con países de la ex URSS. ${ }^{34}$

33 Andorra, Argelia, Azerbaiyán, Bahamas, Bielorrusia, Bután, Bosnia y Herzegovina, las Comoras, Etiopía, Guinea Ecuatorial, Irán, Iraq, Libia, República Árabe Siria, República Libanesa, Santo Tomé y Príncipe, Serbia, Sudán y Uzbekistán.

34 Van Den Bossche, Peter, The Law and..., cit., p. 129. 
Además de los regateos políticos, el proceso también es largo por las complejidades para obtener información y por el tiempo que toma la concreción de reformas institucionales. ${ }^{35}$

El Acuerdo de la OMC admite el abandono por parte del miembro. Desde la fecha de la denuncia del tratado, el miembro debe esperar seis meses para que el abandono se concrete. Por otro lado, la OMC sólo estipula la expulsión para los miembros que se nieguen a adoptar una enmienda; no hay protocolos de expulsión para violadores sistemáticos del acuerdo, ni para países que violan derechos humanos o que cometen crímenes de agresión. ${ }^{36}$ Eso es relevante a la hora de discutir alguna medida futura de flexibilización del llamado "compromiso único" (single undertaking) de la OMC rumbo a alguna geometría variable.

De todos modos, en la práctica, la denuncia del tratado es muy difícil de llevar a cabo considerando que el país que procede a denunciar debe negociar compensaciones con los demás miembros de la OMC.

Actualmente, los países miembros de la $\mathrm{OMC}$, que ingresaron con fecha posterior al 1o. de enero de 1995 son 86 . Sin embargo, el número de adhesiones empieza a disminuir luego de 1997, y se mantiene más o menos constante hasta los días actuales, salvo por la ausencia de adhesiones en el periodo de crisis global, entre 2008 y 2012.

\section{ANÁLISIS DE LOS PROTOCOLOS DE ADHESIÓN}

En este apartado, se analizarán más en detalle los protocolos de adhesión que se encuentran disponibles en la base de datos de la OMC (véase el cuadro 4 a continuación), en búsqueda de características que puedan apoyar el argumento según el cual los protocolos de adhesión contribuyen al proceso de constitucionalización iniciado con la creación de la OMC a la vez que promueven reformas internas en los países, armonizando sus legislaciones sobre la base de estándares comunes determinados por las prácticas del sistema multilateral de comercio.

35 En 2002, el CG elaboró una guía para orientar a los países menos desarrollados en sus procesos de adhesión y así generar mayores facilidades.

36 Den Bossche, Peter van, The Law and..., cit., pp. 119. 
Esta revista forma parte del acervo de la Biblioteca Jurídica Virtual del Instituto de Investigaciones Jurídicas de la UNAM

Cuadro 4. Información sobre la adhesión de países a la OMC

\begin{tabular}{|c|c|c|c|c|c|}
\hline Miembro & $\begin{array}{l}\text { Fecha de } \\
\text { adhesión }\end{array}$ & $\begin{array}{c}\text { Informe del } \\
\text { Grupo de } \\
\text { Trabajo }\end{array}$ & $\begin{array}{c}\text { Lista relativa } \\
\text { a las mercan- } \\
\text { cías }\end{array}$ & $\begin{array}{c}\text { Lista } \\
\text { relativa a los } \\
\text { servicios }\end{array}$ & $\begin{array}{c}\text { Protocolo de } \\
\text { adhesión }\end{array}$ \\
\hline Albania & $\begin{array}{l}8 \text { de sep- } \\
\text { tiembre de } \\
2000\end{array}$ & $\begin{array}{l}\text { WT/ACC/ } \\
\text { ALB/51+ } \\
\text { Corr.1 }\end{array}$ & $\begin{array}{l}\text { WT/ACC/ } \\
\text { ALB/51/ } \\
\text { Add.1 }\end{array}$ & $\begin{array}{l}\text { WT/ACC/ } \\
\text { ALB/51/ } \\
\text { Add.2+ } \\
\text { Corr.2 }\end{array}$ & $\begin{array}{l}\text { WT/ACC/ } \\
\text { ALB/53+ } \\
\text { Corr.1 }\end{array}$ \\
\hline $\begin{array}{l}\text { Arabia Sau- } \\
\text { dita }\end{array}$ & $\begin{array}{l}11 \text { de } \\
\text { diciembre } \\
\text { de } 2005\end{array}$ & $\begin{array}{l}\text { WT/ACC/ } \\
\text { SAU/61 }\end{array}$ & $\begin{array}{l}\text { WT/ACC/ } \\
\text { SAU/61/ } \\
\text { Add.1 }\end{array}$ & $\begin{array}{l}\text { WT/ACC/ } \\
\text { ARM/23/ } \\
\text { Add.2 }\end{array}$ & WT/L/627 \\
\hline Armenia & \begin{tabular}{|l}
5 de \\
febrero de \\
2003 \\
\end{tabular} & $\begin{array}{l}\text { WT/ACC/ } \\
\text { ARM/23 }\end{array}$ & $\begin{array}{l}\text { WT/ACC/ } \\
\text { ARM/23/ } \\
\text { Add.1 }\end{array}$ & $\begin{array}{l}\text { WT/ACC/ } \\
\text { ARM/23/ } \\
\text { Add.2 }\end{array}$ & WT/L/506 \\
\hline Bulgaria & $\begin{array}{l}\text { 1o. de } \\
\text { diciembre } \\
\text { de } 1996\end{array}$ & $\begin{array}{l}\text { WT/ACC/ } \\
\text { BGR/5+ } \\
\text { Corr.1 }\end{array}$ & $\begin{array}{l}\text { WT/ACC/ } \\
\text { BGR/5/ } \\
\text { Add. } 1\end{array}$ & $\begin{array}{l}\text { WT/ACC/ } \\
\text { BGR/5/ } \\
\text { Add. } 2\end{array}$ & $\begin{array}{l}\text { WT/ACC/ } \\
\mathrm{BGR} / 7\end{array}$ \\
\hline Cabo Verde & $\begin{array}{l}23 \text { de julio } \\
\text { de } 2008\end{array}$ & $\begin{array}{l}\text { WT/ACC/ } \\
\mathrm{CPV} / 30\end{array}$ & $\begin{array}{l}\text { WT/ACC/ } \\
\text { CPV/30/ } \\
\text { Add.1 }\end{array}$ & $\begin{array}{l}\text { WT/ACC/ } \\
\text { CPV/30/ } \\
\text { Add.2 }\end{array}$ & WT/L/715 \\
\hline Camboya & $\begin{array}{l}13 \text { de } \\
\text { octubre de } \\
2004\end{array}$ & $\begin{array}{l}\text { WT/ACC/ } \\
\text { KHM/21 }\end{array}$ & $\begin{array}{l}\text { WT/ACC/ } \\
\text { KHM/21/ } \\
\text { Add.1 }\end{array}$ & $\begin{array}{l}\text { WT/ACC/ } \\
\text { KHM/21/ } \\
\text { Add.2 }\end{array}$ & $\begin{array}{l}\text { WT/ } \\
\text { MIN(03)/18 }\end{array}$ \\
\hline China & $\begin{array}{l}11 \text { de } \\
\text { diciembre } \\
\text { de } 2001\end{array}$ & $\begin{array}{l}\text { WT/ACC/ } \\
\text { CHN/49WT/ } \\
\mathrm{MIN}(01) / 3\end{array}$ & $\begin{array}{l}\text { WT/ACC/ } \\
\text { CHN/49/ } \\
\text { Add.1 WT/ } \\
\text { MIN(01)/3/ } \\
\text { Add.1 }\end{array}$ & $\begin{array}{l}\text { WT/ACC/ } \\
\text { CHN/49/ } \\
\text { Add.2 WT/ } \\
\text { MIN(01)/3/ } \\
\text { Add.2 }\end{array}$ & WT/L/432 \\
\hline Croacia & $\begin{array}{l}30 \text { de } \\
\text { noviembre } \\
\text { de } 2000\end{array}$ & $\begin{array}{l}\text { WT/ACC/ } \\
\text { HRV/59 }\end{array}$ & $\begin{array}{l}\text { WT/ACC/ } \\
\text { HRV/59/ } \\
\text { Add.1 }\end{array}$ & $\begin{array}{l}\text { WT/ACC/ } \\
\text { HRV/59/ } \\
\text { Add.2+ } \\
\text { Corr.2 }\end{array}$ & $\begin{array}{l}\text { WT/ACC/ } \\
\mathrm{HRV} / 61\end{array}$ \\
\hline Ecuador & $\begin{array}{l}21 \text { de } \\
\text { enero de } \\
1996\end{array}$ & $\begin{array}{l}\text { WT/L/77+ } \\
\text { Corr.1+Corr. } \\
2+\text { Corr.3 }\end{array}$ & $\begin{array}{l}\text { WT/L/77/ } \\
\text { Add.1+Corr.1 } \\
\text { +Corr.2 }\end{array}$ & $\begin{array}{l}\text { WT/L/77/ } \\
\text { Add.2 }\end{array}$ & $\begin{array}{l}\text { WT/ACC/ } \\
\text { ECU/6 }\end{array}$ \\
\hline Estonia & $\begin{array}{l}13 \text { de } \\
\text { noviembre } \\
\text { de } 1999\end{array}$ & $\begin{array}{l}\text { WT/ACC/ } \\
\text { EST/28+ } \\
\text { Corr.1 }\end{array}$ & $\begin{array}{l}\text { WT/ACC/ } \\
\text { EST/28/Add. } \\
1(\text { part 1)+ } \\
\text { (part } 2+\text { part } 3 \\
+ \text { part 4) }\end{array}$ & $\begin{array}{l}\text { WT/ACC/ } \\
\text { EST/28/ } \\
\text { Add.2+ } \\
\text { Corr.1 }\end{array}$ & $\begin{array}{l}\text { WT/ACC/ } \\
\mathrm{EST} / 30\end{array}$ \\
\hline
\end{tabular}


Esta revista forma parte del acervo de la Biblioteca Jurídica Virtual del Instituto de Investigaciones Jurídicas de la UNAM

\begin{tabular}{|c|c|c|c|c|c|}
\hline $\begin{array}{l}\text { Ex República } \\
\text { Yugoslava de } \\
\text { Macedonia }\end{array}$ & $\begin{array}{l}4 \text { de abril } \\
\text { de } 2003\end{array}$ & $\begin{array}{l}\text { WT/ACC/ } \\
807 / 27\end{array}$ & $\begin{array}{l}\text { WT/ACC/ } \\
807 / 27 / \text { Add.1 }\end{array}$ & $\begin{array}{l}\text { WT/ } \\
\text { ACC/807/ } \\
\text { 27/Add.2 }\end{array}$ & WT/L/494 \\
\hline $\begin{array}{l}\text { Federación de } \\
\text { Rusia }\end{array}$ & $\begin{array}{l}22 \text { de } \\
\text { agosto de } \\
2012\end{array}$ & $\begin{array}{l}\text { WT/ACC/ } \\
\text { RUS/70 WT/ } \\
\operatorname{MIN}(11) / 2\end{array}$ & $\begin{array}{l}\text { WT/ACC/ } \\
\text { RUS/70/ } \\
\text { Add.1 WT/ } \\
\text { MIN(11)/2/ } \\
\text { Add.1 }\end{array}$ & $\begin{array}{l}\text { WT/ACC/ } \\
\text { RUS/70/ } \\
\text { Add.2 WT/ } \\
\text { MIN(11)/ } \\
\text { 2/Add.2 }\end{array}$ & $\begin{array}{l}\text { WT/L/839 } \\
\text { WT/ } \\
\text { MIN(11)/24 }\end{array}$ \\
\hline Georgia & $\begin{array}{l}14 \text { de junio } \\
\text { de } 2000\end{array}$ & $\begin{array}{l}\text { WT/ACC/ } \\
\text { GEO/31 }\end{array}$ & $\begin{array}{l}\text { WT/ACC/ } \\
\text { GEO/31/ } \\
\text { Add.1 }\end{array}$ & $\begin{array}{l}\text { WT/ACC/ } \\
\text { GEO/31/ } \\
\text { Add. } 2\end{array}$ & $\begin{array}{l}\text { WT/ACC/ } \\
\text { GEO/33 }\end{array}$ \\
\hline Jordania & $\begin{array}{l}11 \text { de abril } \\
\text { de } 2000\end{array}$ & $\begin{array}{l}\text { WT/ACC/ } \\
\text { JOR/33+ } \\
\text { Corr.1 }\end{array}$ & $\begin{array}{l}\text { WT/ACC/ } \\
\text { JOR/33/ } \\
\text { Add. } 1\end{array}$ & $\begin{array}{l}\text { WT/ACC/ } \\
\text { JOR/33/ } \\
\text { Add.2 }\end{array}$ & $\begin{array}{l}\text { WT/ACC/ } \\
\text { JOR/35 }\end{array}$ \\
\hline Letonia & $\begin{array}{l}10 \text { de } \\
\text { febrero de } \\
1999\end{array}$ & $\begin{array}{l}\mathrm{WT} / \mathrm{ACC} / \\
\mathrm{LVA} / 32\end{array}$ & $\begin{array}{l}\text { WT/ACC/ } \\
\text { LVA/32/ } \\
\text { Add.1> } \\
\text { Descargar en } \\
\text { formato zip }\end{array}$ & $\begin{array}{l}\text { WT/ACC/ } \\
\text { LVA/32/ } \\
\text { Add.2 }\end{array}$ & $\begin{array}{l}\text { WT/ACC/ } \\
\mathrm{LVA} / 35\end{array}$ \\
\hline Lituania & $\begin{array}{l}31 \text { de } \\
\text { mayo de } \\
2001\end{array}$ & $\begin{array}{l}\text { WT/ACC/ } \\
\text { LTU/52 }\end{array}$ & $\begin{array}{l}\text { WT/ACC/ } \\
\text { LTU/52/ } \\
\text { Add.1+Corr.1 }\end{array}$ & $\begin{array}{l}\text { WT/ACC/ } \\
\text { LTU/52/ } \\
\text { Add.2 }\end{array}$ & $\begin{array}{l}\text { WT/ACC/ } \\
\text { LTU/54 }\end{array}$ \\
\hline Moldavia & $\begin{array}{l}26 \text { de julio } \\
\text { de } 2001\end{array}$ & $\begin{array}{l}\text { WT/ACC/ } \\
\text { MOL/37+ } \\
\text { Corr.4 }\end{array}$ & $\begin{array}{l}\text { WT/ACC/ } \\
\text { MOL/37/ } \\
\text { Add.1 }\end{array}$ & $\begin{array}{l}\text { WT/ACC/ } \\
\text { MOL/37/ } \\
\text { Add.2 }\end{array}$ & $\begin{array}{l}\mathrm{WT} / \mathrm{ACC} / \\
\mathrm{MOL} / 40\end{array}$ \\
\hline Mongolia & \begin{tabular}{|l}
29 de \\
enero de \\
1997 \\
\end{tabular} & $\begin{array}{l}\text { WT/ACC/ } \\
\text { MNG/9+ } \\
\text { Corr.1 }\end{array}$ & $\begin{array}{l}\text { WT/ACC/ } \\
\text { MNG/9/ } \\
\text { Add.1+Corr.1 }\end{array}$ & $\begin{array}{l}\text { WT/ACC/ } \\
\text { MNG/9/ } \\
\text { Add.2 }\end{array}$ & $\begin{array}{l}\text { WT/ACC/ } \\
\mathrm{MNG} / 11\end{array}$ \\
\hline Montenegro & $\begin{array}{l}29 \text { de abril } \\
\text { de } 2012\end{array}$ & $\begin{array}{l}\text { WT/ACC/ } \\
\mathrm{CGR} / 38 \mathrm{WT} / \\
\mathrm{MIN}(11) / 7\end{array}$ & $\begin{array}{l}\text { WT/ACC/ } \\
\text { CGR/38/ } \\
\text { Add.1 WT/ } \\
\text { MIN(11)/7/ } \\
\text { Add.1 }\end{array}$ & $\begin{array}{l}\text { WT/ACC/ } \\
\text { CGR/38/ } \\
\text { Add.2 WT/ } \\
\text { MIN(11)/ } \\
\text { 7/Add.2 }\end{array}$ & $\begin{array}{l}\text { WT/L/841 } \\
\text { WT/ } \\
\text { MIN(11)/28 }\end{array}$ \\
\hline Nepal & $\begin{array}{l}23 \text { de } \\
\text { mayo de } \\
2004\end{array}$ & $\begin{array}{l}\text { WT/ACC/ } \\
\text { NPL/16 }\end{array}$ & $\begin{array}{l}\text { WT/ACC/ } \\
\text { NPL/16/ } \\
\text { Add.1 }\end{array}$ & $\begin{array}{l}\text { WT/ACC/ } \\
\text { NPL/16/ } \\
\text { Add.2 }\end{array}$ & $\begin{array}{l}\text { WT/ } \\
\text { MIN(03)/19 }\end{array}$ \\
\hline Omán & $\begin{array}{l}9 \text { de } \\
\text { noviembre } \\
\text { de } 2000\end{array}$ & $\begin{array}{l}\text { WT/ACC/ } \\
\text { OMN/26 }\end{array}$ & $\begin{array}{l}\text { WT/ACC/ } \\
\text { OMN/26/ } \\
\text { Add. } 1\end{array}$ & $\begin{array}{l}\text { WT/ACC/ } \\
\text { OMN/26/ } \\
\text { Add.2 }\end{array}$ & $\begin{array}{l}\text { WT/ACC/ } \\
\text { OMN/28 }\end{array}$ \\
\hline
\end{tabular}


Esta revista forma parte del acervo de la Biblioteca Jurídica Virtual del Instituto de Investigaciones Jurídicas de la UNAM

\begin{tabular}{|c|c|c|c|c|c|}
\hline Panamá & $\begin{array}{l}6 \text { de sep- } \\
\text { tiembre de } \\
1997\end{array}$ & $\begin{array}{l}\text { WT/ACC/ } \\
\text { PAN/19+ } \\
\text { Corr.1 }\end{array}$ & $\begin{array}{l}\text { WT/ACC/ } \\
\text { PAN/19/Add.1 }\end{array}$ & $\begin{array}{l}\text { WT/ACC/ } \\
\text { PAN/19/ } \\
\text { Add.2 }\end{array}$ & $\begin{array}{l}\text { WT/ACC/ } \\
\text { PAN/21 }\end{array}$ \\
\hline $\begin{array}{l}\text { República } \\
\text { Democrática } \\
\text { Popular Laos }\end{array}$ & $\begin{array}{l}2 \text { de } \\
\text { febrero de } \\
2013\end{array}$ & $\begin{array}{l}\text { WT/ACC/ } \\
\mathrm{LAO} / 45\end{array}$ & $\begin{array}{l}\text { WT/ACC/ } \\
\text { ACC/LAO/ } \\
45 / A d d .1\end{array}$ & $\begin{array}{l}\text { WT/ACC/ } \\
\text { LAO/45/ } \\
\text { Add.2 }\end{array}$ & $\begin{array}{l}\text { WT/ } \\
\text { LET/869 }\end{array}$ \\
\hline $\begin{array}{l}\text { República } \\
\text { Kirguisa }\end{array}$ & $\begin{array}{l}20 \text { de } \\
\text { diciembre } \\
\text { de } 1998\end{array}$ & $\begin{array}{l}\text { WT/ACC/ } \\
\mathrm{KGZ} / 26\end{array}$ & $\begin{array}{l}\text { WT/ACC/ } \\
\text { KGZ/26/ } \\
\text { Add.1+Corr.1 }\end{array}$ & $\begin{array}{l}\text { WT/ACC/ } \\
\text { KGZ/26/ } \\
\text { Add.2 }\end{array}$ & $\begin{array}{l}\text { WT/ACC/ } \\
\text { KGZ/29 }\end{array}$ \\
\hline \multirow[t]{2}{*}{ Samoa } & \multirow[t]{2}{*}{$\begin{array}{l}10 \text { de } \\
\text { mayo de } \\
2012\end{array}$} & $\begin{array}{l}\text { WT/ACC/ } \\
\text { SAM/30 }\end{array}$ & $\begin{array}{l}\text { WT/ACC/ } \\
\text { SAM/30/ } \\
\text { Add.1 }\end{array}$ & $\begin{array}{l}\text { WT/ACC/ } \\
\text { SAM/30/ } \\
\text { Add.2 }\end{array}$ & WT/L/840 \\
\hline & & WT/MIN(11)/1 & $\begin{array}{l}\text { WT/ } \\
\text { MIN(11)/1/ } \\
\text { Add.1 }\end{array}$ & $\begin{array}{l}\text { WT/ } \\
\text { MIN(11)/1/ } \\
\text { Add.2 }\end{array}$ & $\begin{array}{l}\text { WT/ } \\
\text { MIN(11)/27 }\end{array}$ \\
\hline \multirow[t]{2}{*}{ Taipei Chino } & \multirow[t]{2}{*}{$\begin{array}{l}\text { 1o. de } \\
\text { enero de } \\
2002\end{array}$} & $\begin{array}{l}\text { WT/ACC/ } \\
\text { TPKM/18 }\end{array}$ & $\begin{array}{l}\text { WT/ACC/ } \\
\text { TPKM/18/ } \\
\text { Add.1 }\end{array}$ & $\begin{array}{l}\text { WT/ACC/ } \\
\text { TPKM/18/ } \\
\text { Add.2 }\end{array}$ & WT/L/433 \\
\hline & & WT/MIN(01)/4 & $\begin{array}{l}\text { WT/ } \\
\text { MIN(01)/4/ } \\
\text { Add.1 }\end{array}$ & $\begin{array}{l}\text { WT/ } \\
\text { MIN(01)/4/ } \\
\text { Add.2 }\end{array}$ & \\
\hline Tayikistán & $\begin{array}{l}2 \text { de marzo } \\
\text { de } 2013\end{array}$ & $\begin{array}{l}\text { WT/ACC/ } \\
\text { TJK/30 }\end{array}$ & $\begin{array}{l}\text { WT/ACC/ } \\
\text { ACC/TJK/30/ } \\
\text { Add.1 }\end{array}$ & $\begin{array}{l}\text { WT/ACC/ } \\
\text { TJK/30/ } \\
\text { Add.2 }\end{array}$ & $\begin{array}{l}\text { WT/ } \\
\text { LET/878 }\end{array}$ \\
\hline \multirow[t]{2}{*}{ Tonga } & \multirow[t]{2}{*}{$\begin{array}{l}27 \text { de julio } \\
\text { de } 2007\end{array}$} & $\begin{array}{l}\text { WT/ACC/ } \\
\text { TON/17 }\end{array}$ & $\begin{array}{l}\text { WT/ACC/ } \\
\text { TON/17/ } \\
\text { Add.1 } \\
\end{array}$ & $\begin{array}{l}\text { WT/ACC/ } \\
\text { TON/17/ } \\
\text { Add.2 } \\
\end{array}$ & WT/L/644 \\
\hline & & WT/MIN(05)/4 & $\begin{array}{l}\text { WT/ } \\
\text { MIN(05)/4/ } \\
\text { Add.1 }\end{array}$ & $\begin{array}{l}\text { WT/ } \\
\text { MIN(05)/4/ } \\
\text { Add.2 }\end{array}$ & \\
\hline Ucrania & $\begin{array}{l}16 \text { de } \\
\text { mayo de } \\
2008\end{array}$ & $\begin{array}{l}\text { WT/ACC/ } \\
\text { UKR/152 }\end{array}$ & $\begin{array}{l}\text { WT/ACC/ } \\
\text { RUR/152/ } \\
\text { Add.1 }\end{array}$ & $\begin{array}{l}\text { WT/ACC/ } \\
\text { UKR/152/ } \\
\text { Add.2 }\end{array}$ & WT/L/718 \\
\hline Vanuatu & $\begin{array}{l}24 \text { de } \\
\text { agosto de } \\
2012 \\
\end{array}$ & $\begin{array}{l}\text { WT/ACC/ } \\
\text { VUT/17 }\end{array}$ & $\begin{array}{l}\text { WT/ACC/ } \\
\text { VUT/17/ } \\
\text { Add.1 }\end{array}$ & $\begin{array}{l}\text { WT/ACC/ } \\
\text { VUT/17/ } \\
\text { Add.2 }\end{array}$ & WT/L/823 \\
\hline Vietnam & $\begin{array}{l}11 \text { de } \\
\text { enero de } \\
2007\end{array}$ & $\begin{array}{l}\text { WT/ACC/ } \\
\text { VNM/48 }\end{array}$ & $\begin{array}{l}\text { WT/ACC/ } \\
\text { VNM/48/ } \\
\text { Add.1 }\end{array}$ & $\begin{array}{l}\text { WT/ACC/ } \\
\text { VNM/48/ } \\
\text { Add.2 }\end{array}$ & WT/L/662 \\
\hline Yemen & $\begin{array}{l}26 \text { de junio } \\
\text { de } 2014\end{array}$ & $\begin{array}{l}\text { WT/ACC/ } \\
\text { YEM/42 }\end{array}$ & $\begin{array}{l}\text { WT/ACC/ } \\
\text { YEM/42/ } \\
\text { Add.1 }\end{array}$ & $\begin{array}{l}\text { WT/ACC/ } \\
\text { YEM/42/ } \\
\text { Add.2 }\end{array}$ & $\begin{array}{l}\text { WT/ } \\
\text { MIN(13)/24 } \\
\text { WT/L/905 }\end{array}$ \\
\hline
\end{tabular}

FUENTE: OMC, www.wto.org. 
A partir del análisis de los textos disponibles en la base de datos, se observa que las decisiones ministeriales y los protocolos de adhesión siguen un formato más o menos uniforme en todos los protocolos. ${ }^{37} \mathrm{En}$ los considerandos de la decisión, la Conferencia Ministerial hace referencia al Acuerdo de la OMC y sus procedimientos de toma de decisión, a la solicitud de adhesión del país en cuestión y a los resultados del proceso de negociación que estableció las condiciones de adhesión, para luego aprobar la adhesión del país conforme al protocolo, anexo a la decisión.

El texto de los protocolos se divide en cuatro partes (preámbulo y tres partes) y el documento en general tiene tres o cuatro páginas (sin contar las listas de mercancías, servicios y exenciones que van anexadas al protocolo).

El preámbulo hace referencia al Acuerdo de la OMC y sus procedimientos de toma de decisiones, además del informe del Grupo de Trabajo y el resultado de las negociaciones. La parte I, "Disposiciones generales", hace referencia al alcance de los compromisos, los plazos de aplicación de las obligaciones y aclara posibles exenciones o excepciones concedidas al país, como se puede observar en el cuadro 5. La parte II se refiere a las listas de compromisos en mercancías y servicios, aclarando que las listas de mercancías de cada país pasan a ser listas de concesiones y compromisos anexas al GATT de 1994 y las listas de servicios pasan a ser listas de compromisos específicos anexas al GATT. La parte III se refiere a las "Disposiciones finales", donde se detallan los plazos y las condiciones de entrada en vigor, inclusive los procedimientos de depósito ante el director general de la OMC. Las listas de mercancías, servicios y exenciones son anexos de los protocolos.

Como se mencionó anteriormente, los miembros de la OMC deben garantizar que sus legislaciones, regulaciones y disposiciones administrativas estén en conformidad con el Acuerdo. Esto se observa en la extensión de los temas abarcados en los informes de los grupos de trabajo, en el nivel de detalle de las preguntas y respuestas de los miembros y del candidato a la adhesión, además de la duración del proceso de adhesión desde la solicitud del país hasta la aprobación por la Conferencia Ministerial. Los temas que son objeto de las reformas estructurales que los países deben llevar adelante en el proceso de adhesión, además de los principales puntos que son objeto de debate en el proceso de negociación, pueden observarse en el cuadro que sigue.

37 Se analizaron todos los protocolos disponibles en la base de datos de la OMC, detallados en el cuadro 4, supra. 
Esta revista forma parte del acervo de la Biblioteca Jurídica Virtual del Instituto de Investigaciones Jurídicas de la UNAM

Cuadro 5. Lista de temas presentes en los informes de los Grupos de Trabajo

\begin{tabular}{|c|c|}
\hline Tema & Subtemas \\
\hline $\begin{array}{l}\text { Política } \\
\text { económica }\end{array}$ & $\begin{array}{l}\text { Políticas monetaria y fiscal. } \\
\text { Sistema cambiario y de pagos exteriores. } \\
\text { Política de competencia. } \\
\text { Políticas de fijación de precios. } \\
\text { Propiedad estatal, empresas comerciales del Estado, privatiza- } \\
\quad \text { ciones. } \\
\text { Régimen de inversiones. }\end{array}$ \\
\hline $\begin{array}{l}\text { Marco para } \\
\text { la adopción y } \\
\text { aplicación de } \\
\text { políticas }\end{array}$ & $\begin{array}{l}\text { Reformas institucionales, incluso Poder Legislativo, Ejecutivo } \\
\text { y Judicial. }\end{array}$ \\
\hline $\begin{array}{l}\text { Reglamen- } \\
\text { tación de las } \\
\text { importaciones }\end{array}$ & $\begin{array}{l}\text { Régimen de importación. } \\
\text { Arancel de aduanas. } \\
\text { Contingentes arancelarios y exenciones arancelarias. } \\
\text { Otros derechos y gravámenes. } \\
\text { Impuestos al consumo, al valor añadido, a la renta, etcétera. } \\
\text { Derechos y cargos relacionados con las importaciones (por ser- } \\
\quad \text { vicios prestados). } \\
\text { Regímenes de licencias de importación. } \\
\text { Restricciones cuantitativas a las importaciones, incluso prohi- } \\
\quad \text { biciones y contingentes. } \\
\text { Valoración en aduana. } \\
\text { Normas de origen. } \\
\text { Otras medidas en frontera. } \\
\text { Aplicación de impuestos internos a las importaciones. } \\
\text { Inspección previa a la expedición. } \\
\text { Regímenes antidumping, de derechos compensatorios y de sal- } \\
\text { vaguardia. }\end{array}$ \\
\hline $\begin{array}{l}\text { Reglamen- } \\
\text { tación de las } \\
\text { exportaciones }\end{array}$ & $\begin{array}{l}\text { Restricciones a la exportación. } \\
\text { Derechos de exportación. } \\
\text { Subvenciones a la exportación. }\end{array}$ \\
\hline
\end{tabular}




\begin{tabular}{|c|c|}
\hline $\begin{array}{l}\text { Políticas inter- } \\
\text { nas que afectan } \\
\text { al comercio de } \\
\text { mercancías }\end{array}$ & $\begin{array}{l}\text { Políticas industriales, con inclusión de las subvenciones. } \\
\text { Obstáculos técnicos al comercio. } \\
\text { Transparencia. } \\
\text { Aplicación de las obligaciones dimanantes del Acuerdo de la } \\
\text { OMC. } \\
\text { Medidas sanitarias y fitosanitarias. } \\
\text { Medidas en materia de inversiones relacionadas con el comer- } \\
\quad \text { cio. } \\
\text { Zonas francas. } \\
\text { Contratación pública. } \\
\text { Comercio de tránsito. } \\
\text { Política agrícola. } \\
\text { Comercio de aeronaves civiles. }\end{array}$ \\
\hline $\begin{array}{l}\text { Régimen de los } \\
\text { ADPIC }\end{array}$ & $\begin{array}{l}\text { Organismos responsables de la formulación y aplicación de las } \\
\quad \text { políticas. } \\
\text { Participación en acuerdos internacionales sobre propiedad in- } \\
\quad \text { telectual. } \\
\text { Aplicación del trato NMF y trato nacional a los nacionales de } \\
\quad \text { otros países. } \\
\text { Derechos y tasas. } \\
\text { Derechos de autor. } \\
\text { Patentes. } \\
\text { Marcas de fábrica o de comercio. } \\
\text { Indicaciones geográficas. } \\
\text { Dibujos y modelos industriales. } \\
\text { Esquemas de trazado de los circuitos integrados. } \\
\text { Protección de las obtenciones vegetales. } \\
\text { Información no divulgada. } \\
\text { Observancia de la legislación: obligaciones generales, proce- } \\
\quad \text { dimientos civiles y administrativos, medidas provisionales, } \\
\text { prescripciones especiales relacionadas con las medidas en } \\
\text { frontera. } \\
\text { Procedimientos penales. }\end{array}$ \\
\hline $\begin{array}{l}\text { Políticas que } \\
\text { afectan al } \\
\text { comercio de } \\
\text { servicios }\end{array}$ & Reformas y aclaraciones en reglamentaciones nacionales. \\
\hline $\begin{array}{l}\text { Transparencia, } \\
\text { notificaciones }\end{array}$ & $\begin{array}{l}\text { Procedimientos para la publicación de medidas que afecten el } \\
\text { comercio, notificación a la OMC de los cambios en la polí- } \\
\text { tica comercial, etcétera. }\end{array}$ \\
\hline
\end{tabular}


\begin{tabular}{|l|l|}
\hline $\begin{array}{l}\text { Acuerdos co- } \\
\text { merciales }\end{array}$ & $\begin{array}{c}\text { Notificación de los acuerdos existentes y estándares mínimos } \\
\text { que los acuerdos comerciales deben observar. }\end{array}$ \\
\hline
\end{tabular}

FUENTE: Elaboración propia sobre la base de los protocolos de adhesión disponibles en www.wto.org.

Las variaciones con relación al temario son mínimas. En este sentido, se puede observar que para el caso de las economías en transición (Rusia y países de la ex URSS, por ejemplo) hay mayor nivel de obligaciones y de detalle en todo lo relacionado al comercio estatal, las privatizaciones, las políticas sobre competencia, las subvenciones, los gobiernos subnacionales y todo lo atinente a la transición de una economía de planificación centralizada hacia una economía de mercado. En el caso de los reinos (Arabia Saudita y Camboya, por ejemplo), existe un mayor nivel de detalle en las reformas institucionales (creación de ministerios, por ejemplo), y en garantías judiciales de los particulares ante el poder soberano. La única excepción al modelo general de protocolos es China, considerado el caso de adhesión más difícil e importante que se ha llevado a cabo, no tanto por ser la mayor economía del mundo (con gran poder distorsivo en el comercio y las finanzas mundiales), como por la planificación estatal que aún subsiste en dicho país.

El Protocolo de Adhesión de China ${ }^{38}$ tiene 113 páginas sin contar las listas de mercancías y servicios. Esto se debe a que tiene incluido en su texto los compromisos que el país debe observar en puntos centrales relacionados con su sistema de planificación de la economía, por ejemplo: la administración del comercio (zonas económicas especiales, garantía de revisión jurídica de medidas administrativas, no discriminación, acuerdos comerciales especiales, garantía del derecho a tener actividades comerciales), las compras del Estado, las empresas estatales, las medidas no arancelarias, las licencias de importación y exportación, los controles de precios, las subvenciones, los impuestos y las cargas a la importación y la exportación, la agricultura, los obstáculos técnicos al comercio, las medidas sanitarias y fitosanitarias, la comparabilidad de precios para subvenciones y dumping, las salvaguardias, mecanismos de examen de la transición. Además, incluye listas de medidas que se deben eliminar gradualmente, listas de productos sujetos a medidas prohibidas por la OMC (controles de precios, controles de ex-

38 Véase Protocolo de Adhesión de la República Popular China, disponible en www. wto.org. 
portación, etcétera), además de las reservas realizadas por otros miembros sobre medidas restrictivas tomadas en detrimento de China. En su conjunto, el Protocolo es una guía para el gradual acomodamiento de una economía enorme y muy regulada, al marco multilateral de comercio.

Rusia es el otro caso relevante. El país ingresó formalmente a la OMC el 22 de agosto de 2012, luego de 18 años de negociaciones, a partir de la solicitud del país de ingresar a la OMC, en el año 1994. Este momento marcó el comienzo de la integración de este país al comercio internacional luego de su alejamiento por más de 60 años a raíz de la Revolución Comunista. La primera reunión del Grupo de Trabajo para la adhesión de Rusia a la OMC se realizó en Ginebra en julio de 1995, en pleno auge neoliberal del sistema multilateral, el Grupo de Trabajo elevó el informe a la Conferencia Ministerial, que incluyó un proyecto de protocolo de adhesión de la Federación de Rusia a la OMC. ${ }^{39}$ A pesar de que formalmente no escapa de la regla de los protocolos de adhesión y de los temas de la reforma estructural "negociadamente exigida", el Informe del Grupo de Trabajo dedicado a su adhesión tiene más de 650 páginas y es el informe más extenso y detallado de todos los disponibles públicamente. El informe denota la preocupación de los miembros por garantizar el proceso de transición de Rusia, teniendo en consideración principalmente el tamaño de su economía (9a. economía del mundo), la intensidad y magnitud de los subsidios a la energía y a la producción, además del poder simbólico de dicha transición a favor de la hegemonía del modelo librecambista.

El tema agrícola, tema sensible en las negociaciones, se incluyó en ellas en 1998, cuando Rusia presentó su propuesta, que hacía especial hincapié en el mantenimiento de su sistema de subsidios. Según el Protocolo, los rusos dan cinco mil millones de dólares anuales de subsidios al sector agrícola y, a partir del ingreso a la OMC (2012), podrán ampliarlos a nueve mil millones de dólares y a partir de 2013 bajarlos gradualmente a 4.4 mil millones de dólares hasta 2018, con la posibilidad de mantener un sistema de cuotas. Los subsidios agrícolas pudieron mantenerse, e incluso elevarse, debido a que los Estados Unidos y la UE no objetaron seriamente su subsistencia, a cambio de otras reformas más relevantes para la transición de la economía rusa. A su vez, por ejemplo, los países competitivos del Mercosur también aceptaron la permanencia de dichos montos a cambio de cupos de acceso para productos de interés particular.

\footnotetext{
39 Véase Protocolo de Adhesión de Rusia disponible en www.wto.org.
} 


\section{Conclusiones}

El objetivo de este trabajo ha sido analizar en qué medida los protocolos de adhesión de la OMC colaboran en el proceso de constitucionalización del sistema multilateral de comercio, iniciado con la creación de la OMC.

Según lo observado, el proceso de adhesión a la OMC puede dividirse en dos grandes etapas: la etapa de adhesión anterior a la creación de la OMC y la etapa posterior a ella. Los países que participaron de las negociaciones de la Ronda Uruguay, aunque de manera marginal, tenían alguna posibilidad de incidir sobre las normas, para hacerlas más acordes a sus intereses. Si bien dicha posibilidad fue apenas formal en los casos de países con menor poder relativo - considerando su pequeña capacidad de incidencia en la producción de las reglas y el nivel de presión ejercido por los países con mayor poder relativo en ese proceso-, lo cierto es que la capacidad de incidencia se hizo un objetivo aún más lejano para los países candidatos a miembros luego de la creación de la OMC.

Se observa una oleada de adhesiones en los años inmediatamente posteriores a la creación de la OMC, en el periodo que va de 1995 hasta 1997. El número de adhesiones en dicho periodo llega a 132 en total. Si bien esos números extraordinarios han cambiado y la cantidad de adhesiones ha disminuido, la razón es también que quedan pocos países por ingresar al sistema. De todos modos, el número de adhesiones mantiene un ritmo más o menos constante desde 1997, salvo por la parálisis en las adhesiones entre 2008 y 2012, a raíz de la crisis global.

A pesar de la caída en el número de adhesiones a partir de 1997, no hubo cambios en los contenidos. Así, los protocolos son a la vez homogéneos y homogeneizadores, dado que hay un modelo de protocolo que se aplica a todos los países, aunque difiere muy poco entre los casos. Los documentos de los protocolos de adhesión, salvo algunas diferencias para el caso de China, son prácticamente idénticos para todos los países. En el caso de la primera economía mundial, el sistema multilateral tuvo que acordar más excepciones y flexibilidades para acomodar el ingreso del gigante asiático.

De igual manera, los informes de los grupos de trabajo abordan temas similares. Las diferencias observadas tanto en los textos de los protocolos como en los informes de los grupos de trabajo son marginales y se relacionan con el perfil del país que está ingresando y su situación al momento de 
solicitar el ingreso (por ejemplo, si es una economía en transición, un reino, un país importador neto de alimentos o exportador de petróleo) y no con el objetivo final de reformas políticas a ser alcanzado. En este sentido, el punto de llegada hacia donde apuntan las reformas es similar en términos generales para todos. El proceso de adhesión consiste entonces en hacer cumplir, de manera general y uniforme, con los estándares del sistema multilateral de comercio.

El marco teórico de dicho debate es el constitucionalismo internacional que analiza, en clave constitucional, los cambios recientes ocurridos en el sistema internacional, para comprender mejor los procesos de gobernanza global y la evolución del derecho internacional. De acuerdo a ese marco, los procesos de constitucionalización en el sistema internacional se observan cuando ciertas funciones de carácter constitucional migran desde esferas domésticas hacia esferas internacionales, multilaterales y/globales. En cuanto son fenómenos dinámicos, existe asimismo una retroalimentación de ese proceso de constitucionalización que vuelve a la esfera doméstica en forma de obligaciones que el Estado debe cumplir. Dichas obligaciones son uniformes, es decir, cumplen con lineamientos provenientes de esos sistemas "constitucionales" internacionales y establecen estándares a ser cumplidos.

En tal sentido, a partir del análisis realizado en este trabajo, se observa que el proceso de adhesión a la OMC es el gran armonizador de políticas, responsable por profundas reformas estructurales en los países que ingresan. Es decir, por un lado, la creación de la OMC significó una mayor constitucionalización del sistema multilateral de comercio, ${ }^{40}$ toda vez que refleja una migración de funciones inspiradas en valores constitucionales desde la esfera nacional hacia la esfera multilateral.

Por otro lado, ese proceso de constitucionalización se retroalimenta a través del proceso de adhesión, y esa es la función de los protocolos de adhesión, que llevan no sólo a una armonización sino a una homogenización de las reglas por medio del establecimiento de pautas comunes de política comercial y estándares que los Estados deben cumplir para ingresar a la $\mathrm{OMC}$.

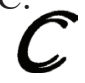

40 Peixoto Batista, Juliana, “Armonización y fragmentación...”, cit.

Fecha de recepción: 17 de noviembre de 2016.

Fecha de dictamen: 18 de mayo de 2017. 